\title{
Evaluation of pharmacy students' knowledge and perceptions of transitions of care services
}

\author{
Tianrui Yang (D), Jessica Wooster \\ Tyler Ben and Maytee Fisch College of Pharmacy, University of Texas, United States
}

\section{Keywords}

Pharmacy curriculum

Pharmacy education

Pharmacist-led service

Transition of care

\author{
Correspondence \\ Tianrui Yang \\ Tyler Ben and Maytee Fisch \\ College of Pharmacy \\ University of Texas \\ United States \\ ycindy1026@gmail.com
}

\begin{abstract}
Introduction: Studies support incorporation of pharmacists and pharmacy students to improve health and financial outcomes during transition of care (TOC). Standardisation of TOC educational training is currently lacking in pharmacy curricula. Methods: This study employed a cross-sectional, descriptive study with a convenience sample at one college of pharmacy. Students participated in an anonymous Qualtrics survey including items on TOC service understanding and educational training. Results are reported as means and standard deviation for continuous data; frequencies and percentages for categorical data. Results: Of 116 survey responses, 112 provided informed consent. Seventy-eight percent of respondents stated they have learned about TOC and $66 \%$ felt they understood what TOC entails. When asked to identify disease states commonly targeted for TOC, $77 \%$ responded incorrectly to this item. When asked to select TOC clinical activities, $66 \%$ incorrectly selected medication dispensing. Ninety-six percent of respondents replied that additional educational training on TOC would be beneficial. Conclusion: There is a discrepancy in students' perception of TOC services with their actual knowledge of TOC services based on survey responses.
\end{abstract}

\section{Introduction}

The Joint Commission defines transitions of care as "the movement of patients between different health care settings or homes as the patient's condition and care changes" (Center for Patient Safety, 2021). Care transitions are a complex and compromising period in a patient's management. Patient safety, compliance with treatment, and outcomes are all affected by the quality of the transition from one provider or facility to the next (Abrashkin et al., 2012). There are several factors that can impact transitions of care, such as communication, patient education, and accountability between healthcare providers (Snow et al., 2009). There is a strong need for pharmacists, which could also include pharmacy students, to have more of a role in transitions of care per the American College of Clinical Pharmacy (American College of Clinical Pharmacy, 2012). Studies have shown that increased interaction between the pharmacist and patient prior to hospital discharge and continued interaction via post-discharge follow up encounters has resulted in positive patient outcomes and reduced hospital readmission rates (Abrashkin et al., 2012).

The integration of transition of care (TOC) into the pharmacy curricula is described by Accreditation Council for Pharmacy Education (ACPE) standards 2016 and Center for the Advancement of Pharmacy Education (CAPE) 2013 Educational Outcomes (Medina et al., 2013; Accreditation Council for Pharmacy Education, 2016). ACPE standard 13.1 highlights TOC as a key element for pharmacy graduates in order to provide "continuity of care" in various healthcare settings. This standard also recommends that students obtain experience in working within an interprofessional patient care team (Accreditation Council for Pharmacy Education, 2016). In CAPE Domain 2, "Essentials for Practice and Care", aligned with the outcome 2.2 medication use systems management, learning objective 2.2.5. states, "Manage health care needs of patients during transitions of care" (Medina et al., 2013). Although these educational outcomes involving care transitions are most commonly achieved during the advanced 
pharmacy practice experience (APPE) curriculum, there remains a need for initial exposure and reinforcement of TOC concepts and clinical activities prior to students starting their APPE rotations. Transitions of care services can help enhance pharmacy students' learning and involvement in APPE rotations (Vavra et al., 2018). This can be done by understanding how a pharmacist can positively impact patients and other healthcare professionals' choices by offering services that include but are not limited to drug-drug interventions, medication counselling, medication discrepancies and disease state management (Serag-Bolos et al., 2017; Brantley et al., 2018). Other studies suggest that TOC services allow pharmacy students to develop skills such as medication reconciliation, which can help positively influence patient care outcomes (Brantley et al., 2018; Vavra et al., 2018). Incorporation of pharmacy students into TOC services have been evidenced in the literature to result in improved patient safety through the identification of discrepancies, increased prescription capture via meds-to-beds service, and enhanced discharge education and phone follow-up that resulted in reduced 30-day readmissions (Walker, Tucker Jones, \& Mason, 2010; Hertig et al., 2017; Rogers et al., 2017; Shaver et al., 2019; Vavra et al., 2018).

Incorporating pharmacy students into TOC services can result in positive economic outcomes for the institution offering this service. This can be done by increasing prescription capture rates of discharge prescriptions, decreasing emergency room visits, and helping patients and healthcare institutions with cost savings through reduced length of hospital stay and reductions in hospital readmissions (Conliffe et al., 2019). John Hopkins Health System has implemented a model which includes pharmacy services employed by a pharmacist, fourth-year pharmacy student, and a pharmacy technician in the TOC process to enhance multidisciplinary collaboration and decrease hospital readmissions (Gilmore et al., 2015). By incorporating more experiential opportunities for education in transitions of care, the pharmacy student can acquire the invaluable skills of offering patient-centred care within and across healthcare settings.

As described in the current literature, pharmacy didactic content and skills associated with TOC services includes medication errors, professional communication, medication history and reconciliation, counselling, and interprofessional team collaborative efforts (Kiersma et al., 2009; Vyas et al., 2012; Kirwin et al., 2013; Sando et al., 2013; Hagemeier et al., 2014; Volino et al., 2014; Cooper \& Bradley, 2019). Students should be exposed to problems and solutions related to TOC and be provided opportunities for pharmacy students to practise such skills in the classroom setting; however, this appears to be lacking with the current pharmacy curriculum (Serag-Bolos et al., 2017). By improving pharmacy students' understanding of transitions of care interventions, it can help reduce preventable adverse events that could arise by moving patients from different levels of care. This study will assess pharmacy student training and education on transitions of care of pharmacy services in both didactic and experiential education settings.

\section{Methods}

A cross-sectional survey was developed by the authors to capture students' perceptions of TOC learning during pharmacy school. The survey included ten questions to assess students' perception of their current TOC learning, their view of TOC benefits, and their knowledge of TOC services. All perception questions were formatted via a 7-point Likert scale with $1=$ strongly disagree, and 7 = strongly agree. Knowledge questions were formatted as "select all the apply" questions. The survey questions are included in Appendix A. Survey was created electronically with Qualtrics and distributed via Canvas, an online learning management system for students. All students, first through the fourth year (P1 - P4) from the University of Texas at Tyler Ben and Maytee Fisch College of Pharmacy, were recruited to participate in this study. Survey responses were collected from 4 March to 1 May 2020. Informed consent was obtained as a survey item. While participants were asked to answer each question, they were able to skip questions if preferred. Descriptive statistics were used to analyse survey participants' responses.

\section{Results}

Two hundred and twenty-four students were invited to participate in the survey, and 112 respondents participated, providing a $50 \%$ response rate. Respondents stated they have previously learned about TOC in the classroom (51.8\%), during experiential education (56.25\%), or pharmacy-related job (16.1\%), while $22.3 \%$ claimed they had not learned about TOC in pharmacy school or a pharmacy-related job. Sixty-six per cent felt they understood what TOC entailed, and $47 \%$ of students stated they could explain what TOC pharmacy services entail. However, when asked to identify TOC clinical activities, $66.1 \%$ of students selected medication dispensing and $42.9 \%$ selected pharmacokinetic dosing (Table I). Additionally, when asked to identify disease states commonly targeted for TOC services, students incorrectly identified asthma (76.8\%), arrhythmia (76.8\%), and influenza (41.1\%). 
The majority of students saw the value of TOC services to positively impact patient care outcomes $(79.5 \%)$ and to reduce healthcare costs $(76.8 \%)$. Students agreed that further education on TOC pharmacy services would be beneficial to their learning in didactic (79.5\%), experiential (78.6\% IPPE, 83\% APPE), and after graduation (67\%). Table I summarises the TOC knowledge survey item responses.

Table 1: TOC knowledge questions result

\begin{tabular}{|c|c|}
\hline TOC Knowledge questions & $\begin{array}{l}\text { Student response, } \\
\text { n (\%) }\end{array}$ \\
\hline \multicolumn{2}{|c|}{ Which of the following are considered transitions of care } \\
\hline Medication education & $104(92.9)$ \\
\hline Disease state education & $100(89.3)$ \\
\hline Hospital discharge education & $100(89.3)$ \\
\hline Post-hospital discharge phone calls & $96(85.7)$ \\
\hline $\begin{array}{l}\text { Post-hospital discharge follow-up } \\
\text { physician visits }\end{array}$ & $91(81.3)$ \\
\hline Medication dispensing & $74(66.1)$ \\
\hline Meds-to-beds service & $72(64.3)$ \\
\hline Home visits & $76(67.9)$ \\
\hline Pharmacokinetic dosing & 48 (42.9) \\
\hline Medication Reconciliation & $87(77.7)$ \\
\hline Patient assistance programs & $82(73.2)$ \\
\hline Appointment scheduling & $66(58.9)$ \\
\hline \multicolumn{2}{|c|}{$\begin{array}{l}\text { Which of the following health care members are involved in } \\
\text { transitions of care services? (select all that apply) }\end{array}$} \\
\hline Physicians & $105(93.8)$ \\
\hline Nurses & $105(93.8)$ \\
\hline Pharmacists & $111(99.1)$ \\
\hline Community health workers & $78(87.5)$ \\
\hline Social workers & $84(75.9)$ \\
\hline Case management & $77(68.8)$ \\
\hline Physical therapists & 85 (75.9) \\
\hline Occupational therapists & $81(72.3)$ \\
\hline Home health providers & $97(86.6)$ \\
\hline \multicolumn{2}{|c|}{$\begin{array}{l}\text { Which locations do the transition of care services occur? (select } \\
\text { all that apply) }\end{array}$} \\
\hline Hospital & $103(92)$ \\
\hline Clinic & $96(85.7)$ \\
\hline Patients' home & $87(77.7)$ \\
\hline Community pharmacy & $78(69.6)$ \\
\hline Rehabilitation facility & $94(83.9)$ \\
\hline Assisted living facility & $88(78.6)$ \\
\hline Skilled nursing facility & $93(83)$ \\
\hline Long-term care facility & $83(74.1)$ \\
\hline
\end{tabular}

\section{Discussion}

Current literature on pharmacy students' knowledge and perception regarding pharmacy TOC services is limited to descriptive studies on simulation activities and elective course or class design ("Hot Topics in Healthcare: Transitions of Care: The need for a more effective approach to continuing patient care," n.d.; Serag-Bolos et al., 2017; Snow et al., 2009). This is the first study to the authors' knowledge that assessed students' overall perception of TOC education. The results indicate that while the majority of the students perceive that they have had exposure to TOC during the classroom, experiential education, or pharmacyrelated jobs, they failed to accurately identify the relevant disease states and activities involved with TOC services. This mismatch in the students' perception of their level of understanding in the TOC services and their knowledge of what TOC services entail support the incorporation of TOC education into the pharmacy curricula as TOC pharmacy services are rapidly growing in across all healthcare settings.

There are currently no standardised training opportunities offered by schools of pharmacy. TOC pharmacists are typically trained through postgraduate residency training. Currently, most training opportunities arise during APPE and possibly introductory pharmacy practice experiences (IPPE) during school. If such rotation types are offered, it is typically an APPE elective rotation that the students may choose to participate in. There is a need for further education and training on TOC pharmacy services in both experiential and didactic settings; however, barriers exist that may make this difficult to incorporate. Barriers to establishing standardised TOC classes within the didactic curriculum include uncertainty of placement within the curriculum, resistance by faculty and administrators, inadequate infrastructure to accommodate TOC delivery, unavailability of TOC faculty, and resistance by other healthcare providers were reported (Eltaki et al., 2018).

There is very limited literature on the incorporation of TOC education into the didactic curriculum of pharmacy education. A study by Serag-Bolos and authors investigated the impact of a simulation TOC lab in a curriculum where TOC education is embedded throughout the P1 through P3 classes. They concluded that TOC education integrated into the didactic curriculum improves students' general understanding of a pharmacists' involvement in the TOC process (Serag-Bolos et al., 2017). This finding contrasts with this study since the results demonstrated a lack of understanding of TOC services by the students. This is likely due to the limited TOC education provided in the didactic curriculum at the college. This further supports that incorporating TOC classes throughout the curriculum will likely improve students' understanding of TOC services. While there was a lack of understanding, the students agree that TOC services are beneficial financially and therapeutically. The 
majority of the students agreed that they would benefit from further training in this area. Interestingly, when Eltaki and the authors investigated allocation of faculty and curricular time to the teaching of TOC concepts by 36 colleges of pharmacy, $47 \%$ of these schools employed TOC faculty but the median total curriculum hours dedicated to teaching TOC was only four hours (Eltaki et al., 2018). Crucial pharmacy skills such as medication reconciliation are only taught didactically or through lab activities in 53\% of these schools. These results further illustrate a mismatch between the current curriculum design and the TOC skills that is currently frequently utilised in different pharmacy settings.

Study limitations include generalisability due to low response rates and convenience sampling by online survey distribution to pharmacy students at one college. Therefore, these responses may not reflect the experiences and knowledge of other student pharmacists. As this study was conducted at a single college of pharmacy, the generalisability of results may be limited. Future research is needed to determine a universal definition of TOC services to be provided by pharmacy personnel and the best methods for training students to ensure competence in these tasks. There is currently only one study that described a TOC elective course delivered to third-year pharmacy students (Sen et al., 2016). This study can be referred to for guidance on how and when to incorporate TOC activities, but more studies are needed to optimise TOC education within the didactic curriculum.

\section{Conclusion}

Despite students' perception of their understanding of TOC services, the results supported that there is a lack of understanding and competency in this area. There is limited literature on how to best incorporate TOC training within pharmacy didactic or experiential curriculum. Future studies should explore when and how to best incorporate TOC pharmacy services into the pharmacy curriculum, as well as what educational content and skills should be included on this topic.

\section{References}

Abrashkin, K.A., Cho, H.J., Torgalkar, S., \& Markoff, B. (2012). Improving transitions of care from hospital to home: what works? The Mount Sinai Journal of Medicine, New York, 79(5), 535-544. https://doi.org/10.1002/msj.21332

Accreditation Council for Pharmacy Education. (2016). Accreditation Standards and Key Elements for the Professional Program in Pharmacy Leading to the Doctor of
Pharmacy Degree. Available at: http://www.acpeaccredit.org/pdf/Standards2016FINAL.pdf

American College of Clinical Pharmacy, Hume, A.L., Kirwin, J., Bieber, H.L., Couchenour, R.L., Hall, D.L., Kennedy, A.K., LaPointe, N. M., Burkhardt, C. D., Schilli, K., Seaton, T., Trujillo, J., \& Wiggins, B. (2012). Improving care transitions: current practice and future opportunities for pharmacists. Pharmacotherapy, 32(11), e326-37. https://doi.org/10.1002/phar.1215

Brantley, A.F., Rossi, D.M., Barnes-Warren, S., Francisco, J.C., Schatten, I., \& Dave, V. (2018). Bridging gaps in care: Implementation of a pharmacist-led transitions-of-care program. American Journal of Health-System Pharmacy, 75(5 Suppleundefined1), S1-S5.

https://doi.org/10.2146/ajhp160652

Conliffe, B., VanOpdorp, J., Weant, K., VanArsdale, V., Wiedmar, J., \& Morgan, J. (2019). Impact of an Advanced Pharmacy Practice Experience Student-Run "Meds 2 Beds" and Discharge Counseling Program on Quality of Care. Hospital pharmacy, 54(5), 314-322. https://doi.org/10.1177/0018578718791519

Cooper, J.B., \& Bradley, C.L. (2019). Design of hospital errors and omissions activities that include patient-specific medication related problems. Currents in pharmacy teaching \& learning, 11(1), 66-75.

https://doi.org/10.1016/j.cptl.2018.09.018

Eltaki, S.M., Singh-Franco, D., Leon, D.J., Nguyen, M.-O., \& Wolowich, W.R. (2018). Allocation of faculty and curricular time to the teaching of transitions of care concepts by colleges of pharmacy. Currents in pharmacy teaching \& learning, 10(6), 701-711.

https://doi.org/10.1016/j.cptl.2018.03.014

Gilmore, V., Efird, L., Fu, D., LeBlanc, Y., Nesbit, T., \& Swarthout, M. (2015). Implementation of transitions-of-care services through acute care and outpatient pharmacy collaboration. American Journal of Health-System Pharmacy, 72(9), 737-744. https://doi.org/10.2146/ajhp140504

Hagemeier, N.E., Hess, R., Hagen, K.S., \& Sorah, E.L. (2014). Impact of an interprofessional communication course on nursing, medical, and pharmacy students' communication skill self-efficacy beliefs. American journal of pharmaceutical education, 78(10), 186.

https://doi.org/10.5688/ajpe7810186

Hertig, R., Ackerman, R., Zagar, B., \& Tart, S. (2017). Pharmacy student involvement in a transition of care program. Currents in pharmacy teaching \& learning, 9(5), 841-847. https://doi.org/10.1016/j.cptl.2017.06.004

Center for Patient Safety. (2021). Hot Topics in Healthcare: Transitions of Care: The need for a more effective approach to continuing patient care. Available at: https://www.centerforpatientsafety.org/resource/hottopics-in-healthcare-transitions-of-care-the-need-for-amore-effective-approach-to-continuing-patient-care/

Kiersma, M.E., Darbishire, P.L., Plake, K.S., Oswald, C., \& Walters, B.M. (2009). Laboratory session to improve firstyear pharmacy students' knowledge and confidence concerning the prevention of medication errors. American journal of pharmaceutical education, 73(6), 99. https://doi.org/10.5688/aj730699 
Kirwin, J.L., DiVall, M.V., Guerra, C., \& Brown, T. (2013). A simulated hospital pharmacy module using an electronic medical record in a pharmaceutical care skills laboratory course. American journal of pharmaceutical education, 77(3), 62. https://doi.org/10.5688/ajpe77362

Medina, M.S., Plaza, C.M., Stowe, C.D., Robinson, E.T., DeLander, G., Beck, D.E., Melchert, R.B., Roche, V.F., Gleason, B.L., Strong, M.N., Bain, A., Meyer, G.E., Dong, B.J., Rochon, J., \& Johnston, P. (2013). Center for the Advancement of Pharmacy Education 2013 educational outcomes. American journal of pharmaceutical education, 77(8), 162. https://doi.org/10.5688/ajpe778162

Rogers, J., Pai, V., Merandi, J., Catt, C., Cole, J., Yarosz, S., Wehr, A., Durkin, M.K., Kaczor, C. (2017). Impact of a pharmacy student-driven medication delivery service at hospital discharge. American Journal of Health-System Pharmacy, 74(5 Suppleundefined1), S24-S29. https://doi.org/10.2146/ajhp150613

Sando, K.R., Elliott, J., Stanton, M.L., \& Doty, R. (2013). An educational tool for teaching medication history taking to pharmacy students. American journal of pharmaceutical education, 77(5), 105. https://doi.org/10.5688/ajpe775105

Sen, S., Hadley, D., Patterson, B.J., \& Patel, R.V. (2016). Development and implementation of a transitions of care elective course. Currents in Pharmacy Teaching and Learning, 8(3), 380-390.

https://doi.org/10.1016/j.cptl.2016.02.019

Serag-Bolos, E.S., Miranda, A.C., Gelot, S.R., Dharia, S.P., \& Shaeer, K.M. (2017). Assessing students' knowledge regarding the roles and responsibilities of a pharmacist with focus on care transitions through simulation. Currents in pharmacy teaching \& learning, 9(4), 616-625. https://doi.org/10.1016/j.cptl.2017.03.020

Shaver, A., Morano, M., Pogodzinski, J., Fredrick, S., Essi, D., \& Slazak, E. (2019). Impact of a community pharmacy transitions-of-care program on 30-day readmission. Journal of the American Pharmacists Association, 59(2), 202-209. https://doi.org/10.1016/j.japh.2018.10.011

Snow, V., Beck, D., Budnitz, T., Miller, D.C., Potter, J., Wears, R.L., Weiss, K.B., Williams, M.V., (2009). Transitions of Care Consensus Policy Statement American College of PhysiciansSociety of General Internal Medicine-Society of Hospital Medicine-American Geriatrics Society-American College of Emergency Physicians-Society of Academic Emergency Medicine. Journal of General Internal Medicine, 24(8), 971976. https://doi.org/10.1007/s11606-009-0969-x

Vavra, K., Paluzzi, M., de Voest, M., Raguckas, S., \& Slot, M. (2018). Preliminary findings from a student pharmacist operated transitions of care pilot service. Currents in pharmacy teaching \& learning, 10(1), 78-84. https://doi.org/10.1016/j.cptl.2017.09.018

Volino, L.R., Das, R.P., Mansukhani, R.P., \& Cosler, L.E. (2014). Evaluating the potential impact of pharmacist counseling on medication adherence using a simulation activity. American journal of pharmaceutical education, 78(9), 169. https://doi.org/10.5688/ajpe789169

Vyas, D., McCulloh, R., Dyer, C., Gregory, G., \& Higbee, D. (2012). An interprofessional course using human patient simulation to teach patient safety and teamwork skills. American journal of pharmaceutical education, 76(4), 71. https://doi.org/10.5688/ajpe76471

Walker, P.C., Tucker Jones, J.N., \& Mason, N.A. (2010). An advanced pharmacy practice experience in transitional care. American journal of pharmaceutical education, 74(2), 20. https://doi.org/10.5688/aj740220 


\section{Appendix A: Survey questions}

1. I understand what "transitions of care" means. Scale of 1-7 strongly agree > strongly disagree

2. I can explain "transitions of care" pharmacy services. Scale of 1-7 strongly agree > strongly disagree

3. I have learned about transitions of care in the following pharmacy school settings (select all that apply):
a. Classroom
b. IPPE rotation
c. APPE rotation
d. Past or current job in pharmacy field
e. I have not learned about transitions of care

4. Transitions of care pharmacy services are beneficial to patient care health outcomes.

Scale of 1-7 strongly agree > strongly disagree

5. Transitions of care pharmacy services reduce costs of health care.

Scale of 1-7 strongly agree $>$ strongly disagree

6. Education on pharmacy transitions of care services would be beneficial to my learning in the following settings (select all that apply)
a. Classroom
b. IPPE rotation
c. APPE rotation
d. After graduation
e. This would not be beneficial to my learning

7. The following health conditions are most commonly included in transitions of care services (select all that apply)
a. Heart Failure
b. Myocardial Infarction
c. Arrythmia
d. Chronic Obstructive Pulmonary Disease
e. Asthma
f. Pneumonia
g. Influenza

8. Which of the following are considered transitions of care clinical activities? (select all that apply)
a. Medication education
b. Disease state education
c. Hospital discharge education
d. Post-hospital discharge phone calls
e. Post-hospital discharge follow-up physician visits
f. Medication dispensing
g. Meds-to-beds service
h. Home visits
i. Pharmacokinetic dosing
j. Medication Reconciliation
k. Patient assistance programs
I. Appointment scheduling

9. Which of the following health care members are involved in transitions of care services? (select all that apply)

a. Physicians

b. Nurses

c. Pharmacists

d. Community health workers

e. Social workers

f. Case management

g. Physical therapists

h. Occupational therapists

i. Home health providers

10. Which locations do transition of care services occur? (select all that apply)
a. Hospital
b. Clinic
c. Patient's Home
d. Community Pharmacy
e. Rehabilitation Facility
f. Assisted Living Facility
g. Skilled Nursing Facility
h. Long-term Care Facility 